\title{
Supplement to Revisiting the contribution of land transport and shipping emissions to tropospheric ozone
}

\author{
Mariano Mertens \\ Institut für Physik der Atmosphäre \\ DLR-Oberpfaffenhofen
}

mariano.mertens@dlr.de 


\section{Contents}

S1 Average contributions for July (Tagging)

S2 Average Impacts for July (Perturbation)

S3 Comparision to RC1SD-base10a simulation 


\section{S1 Average contributions for July (Tagging)}

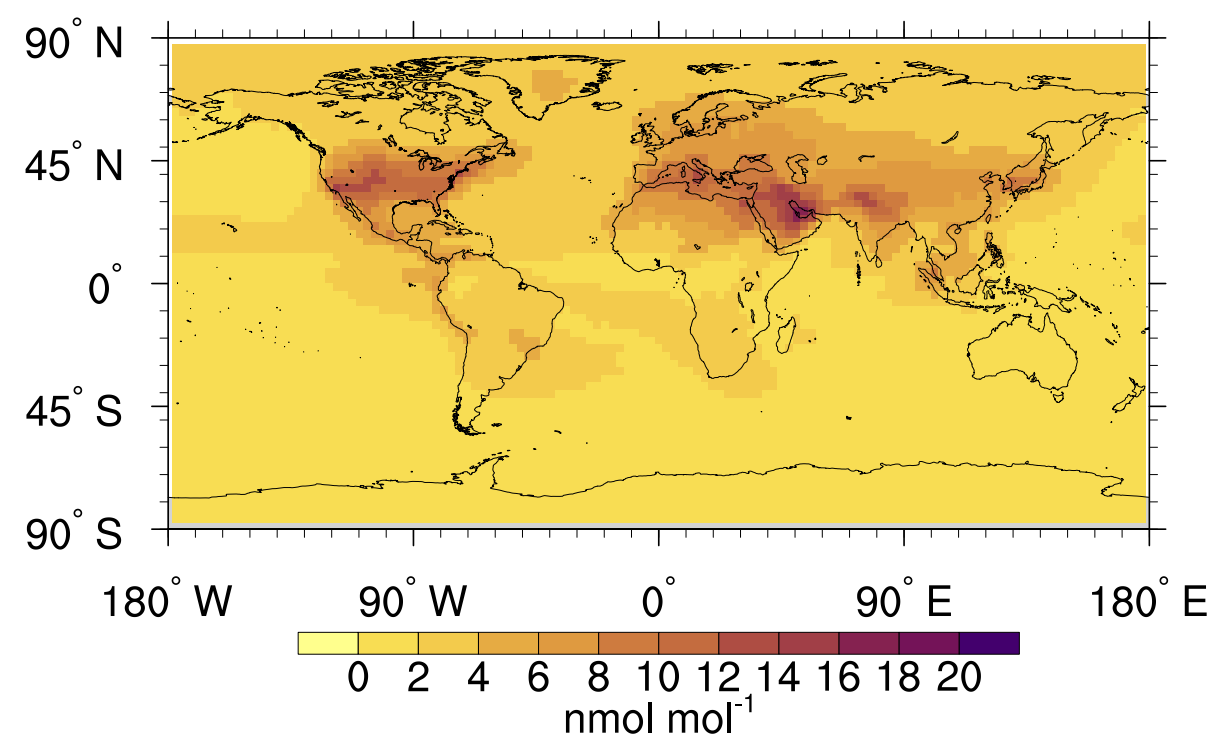

Figure S1: Multi-annual average (2006-2010) of the absolute contribution of land transport emissions $\left(\mathrm{O}_{3}^{\text {tra }}\right.$, in nmol mol${ }^{-1}$ ) for July.

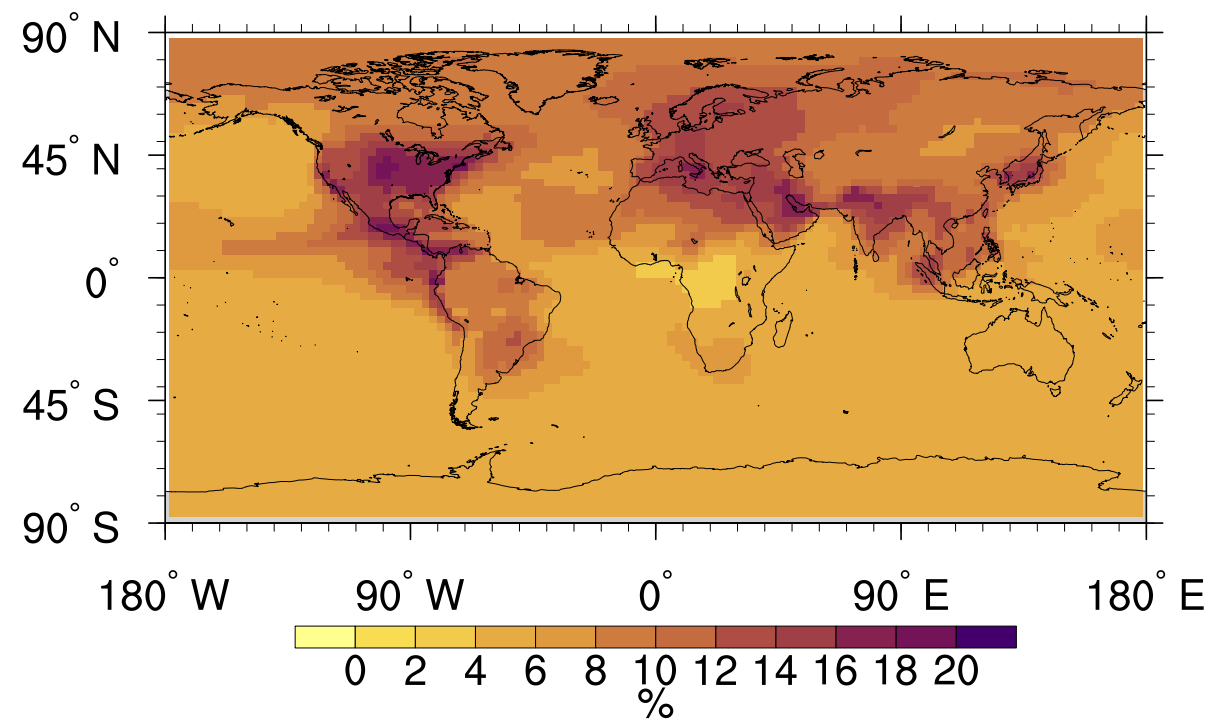

Figure S2: Multi-annual average (2006-2010) of the relative contribution of land transport emissions $\left(\mathrm{O}_{3}^{\text {tra }}\right.$ in $\left.\%\right)$ for July. 


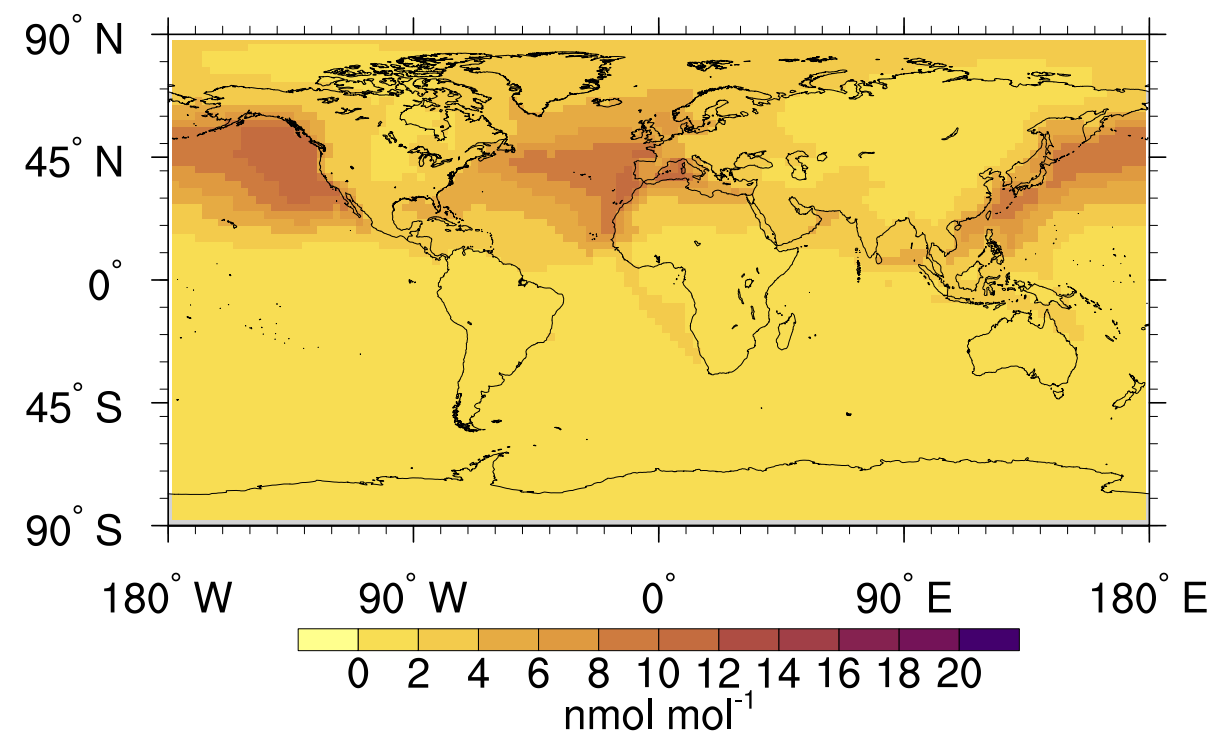

Figure S3: Multi-annual average (2006-2010) of the absolute contribution of shipping emissions $\left(\mathrm{O}_{3}^{\text {shp }}\right.$, in $\left.\mathrm{nmol} \mathrm{mol}^{-1}\right)$ for July.

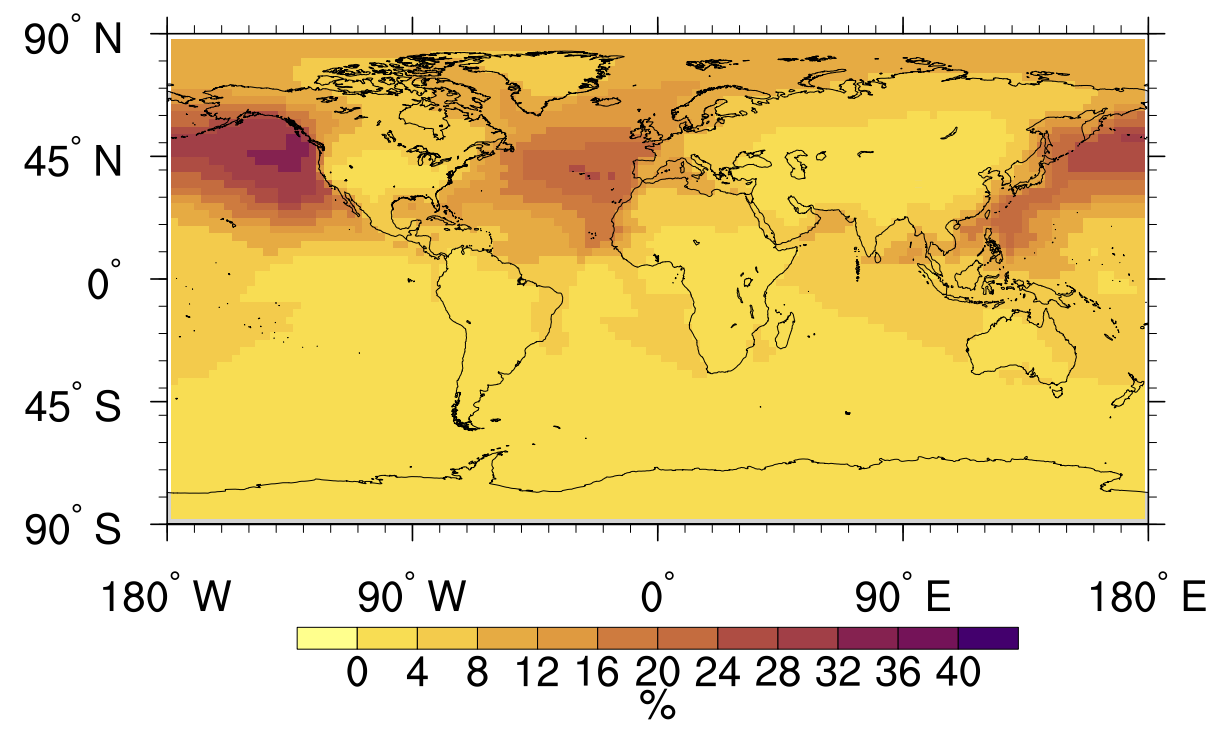

Figure S4: Multi-annual average (2006-2010) of the relative contribution of shipping emissions $\left(\mathrm{O}_{3}^{\text {shp }}\right.$, in \%) for July. 


\section{S2 Average Impacts for July (Perturbation)}

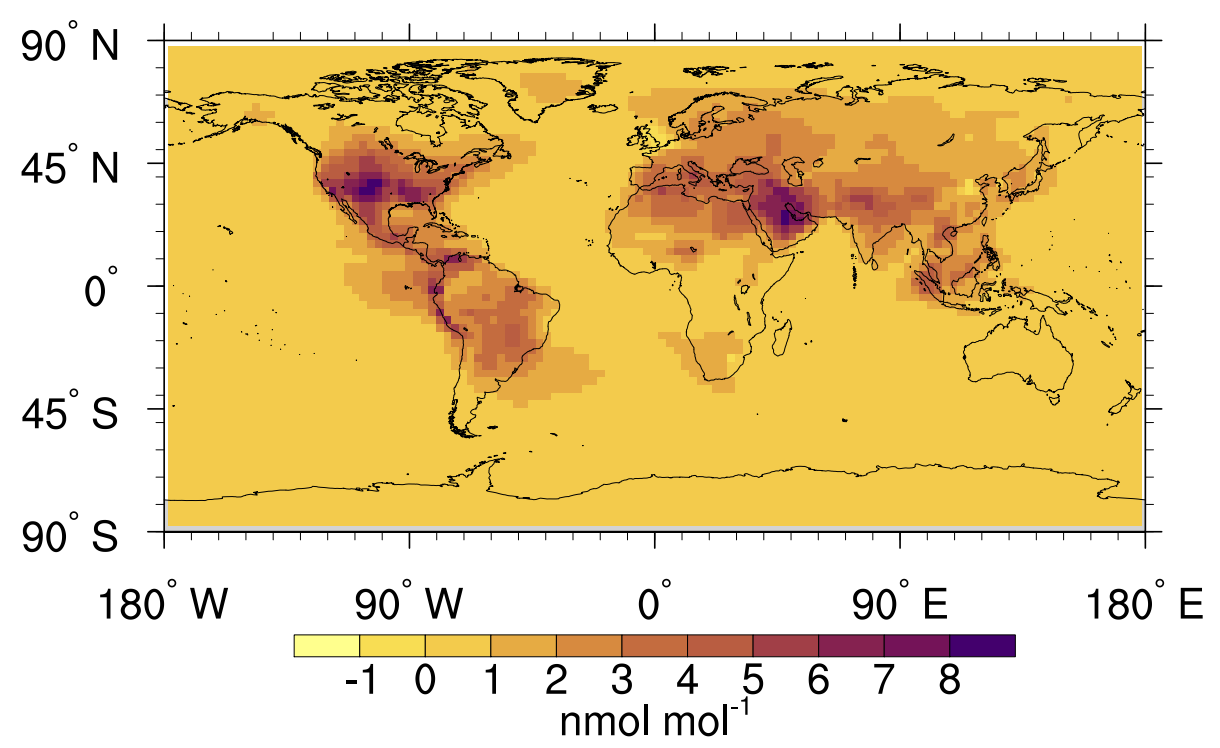

Figure S5: Multi-annual average (2006-2010) of the absolute impact of land transport emissions (in nmol mol ${ }^{-1}$ ) for July. Values are diagnosed using a $5 \%$ perturbation. 


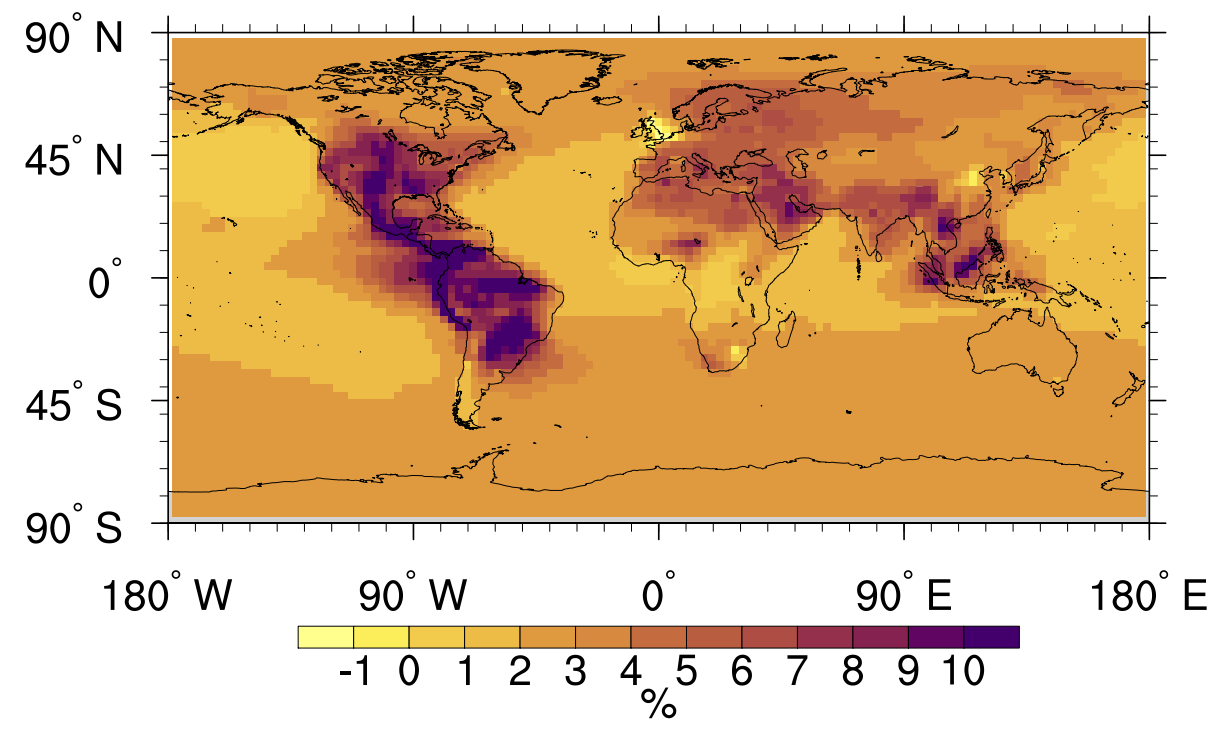

Figure S6: Multi-annual average (2006-2010) of the relative impact of land transport emissions ( in \%) for July. Values are diagnosed using a $5 \%$ perturbation.

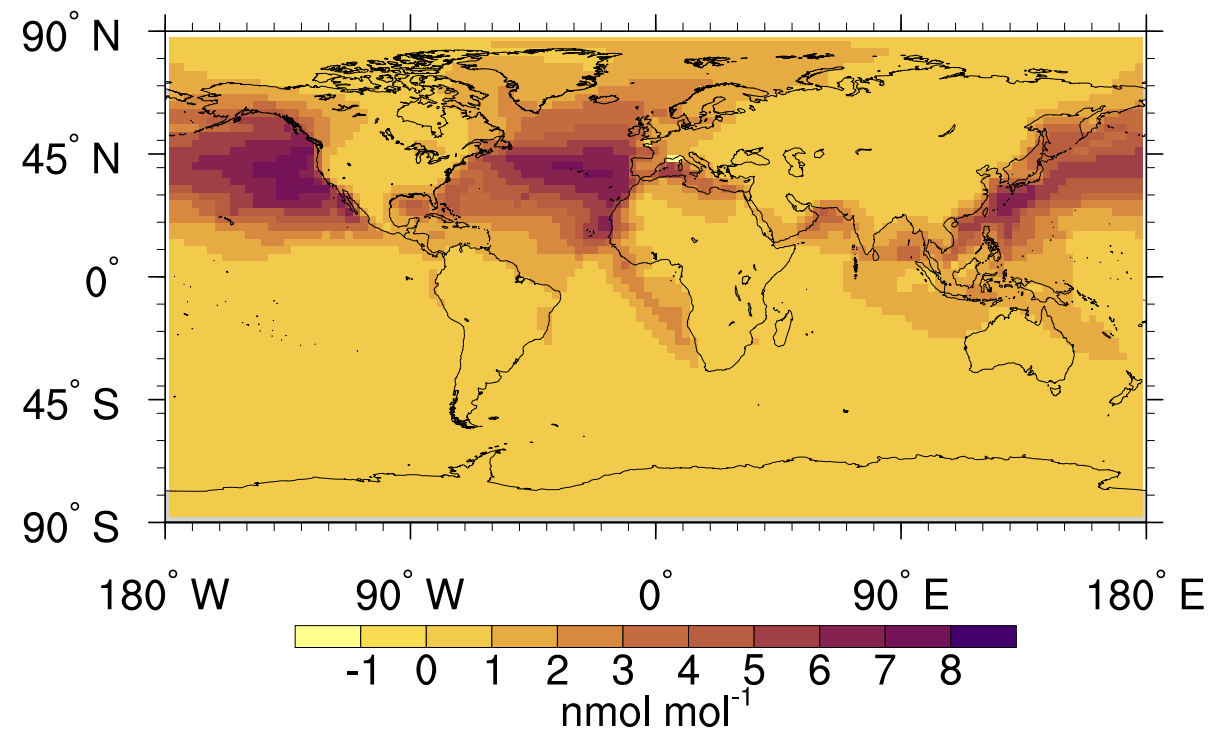

Figure S7: Multi-annual average (2006-2010) of the absolute impact of shipping emissions (in nmol mol ${ }^{-1}$ ) for July. Values are diagnosed using a $5 \%$ perturbation. 


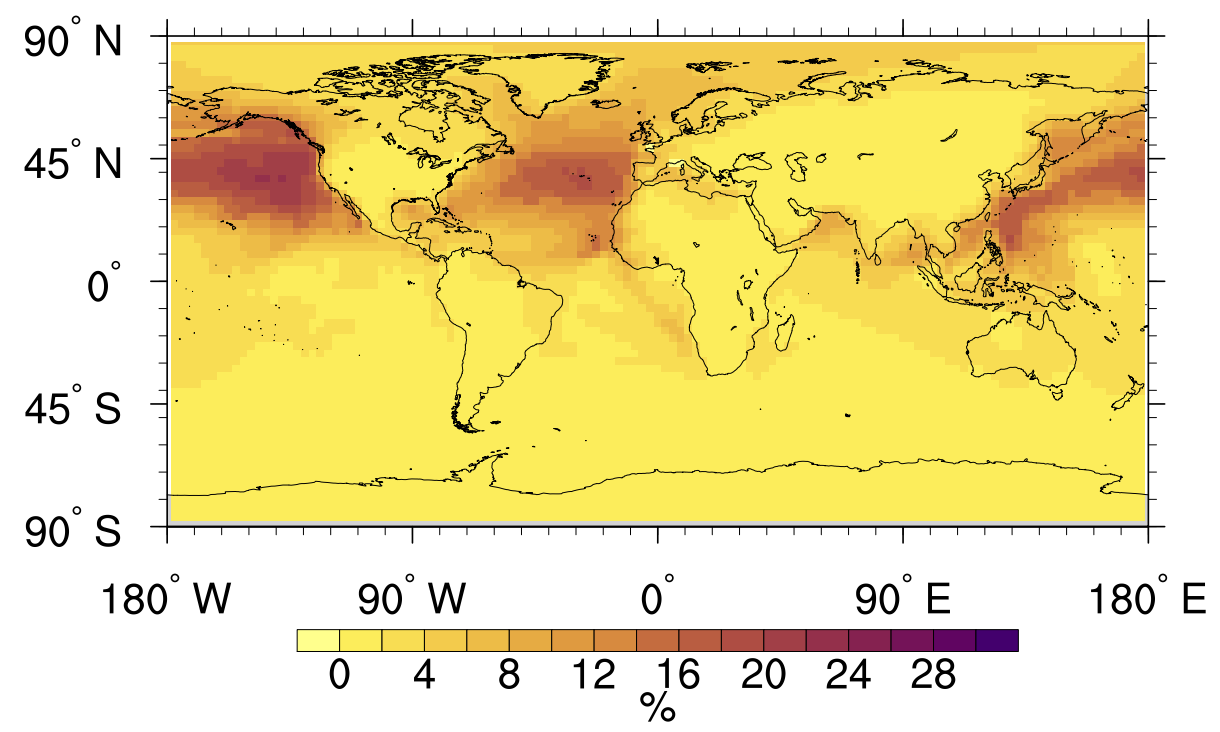

Figure S8: Multi-annual average (2006-2010) of the relative impact of shipping emissions ( in \%) for July. Values are diagnosed using a $5 \%$ perturbation. 


\section{S3 Comparision to RC1SD-base10a simulation}

The following figures show the difference between the BASE simulation and the RC1SD-base10a simulation described by Jöckel et al. (2016). Shown are average values (2005-2010) of the temperature as well as mixing rations of CO, $\mathrm{NO}_{\mathrm{x}}$ and $\mathrm{O}_{3}$. Both simulations differ only slightly. A detailed comparison to observations of the RC1SD-base10a simulation is given by Jöckel et al. (2016).

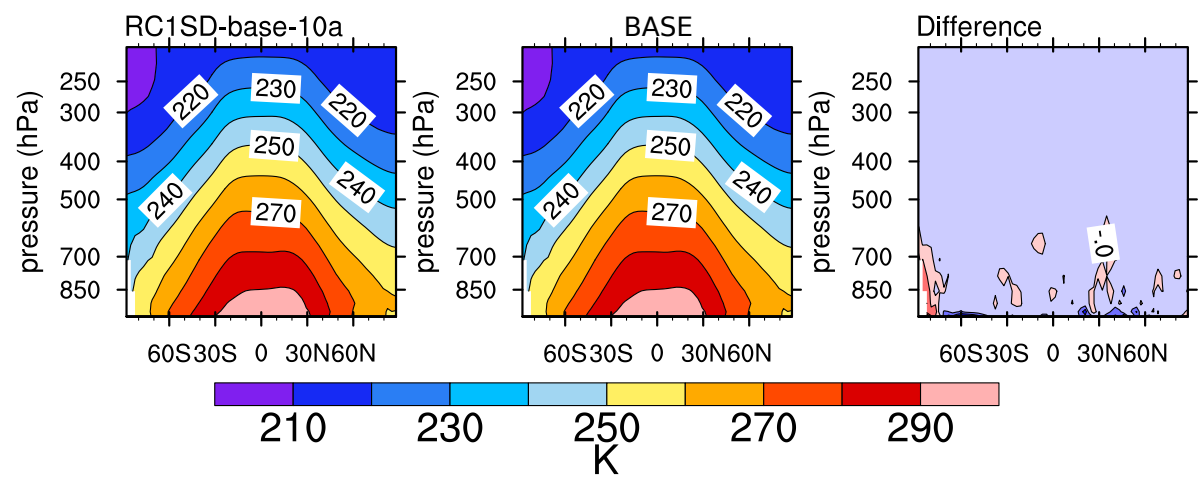

Figure S9: Zonal averaged temperature (in K) for 2005-2010. The left plot shows the value for the RC1SD-base10a, the middle plot the value for the simulation $B A S E$ and the right plot the absolut difference between the two fields. The colour bar indicates only the values for the first two plots.

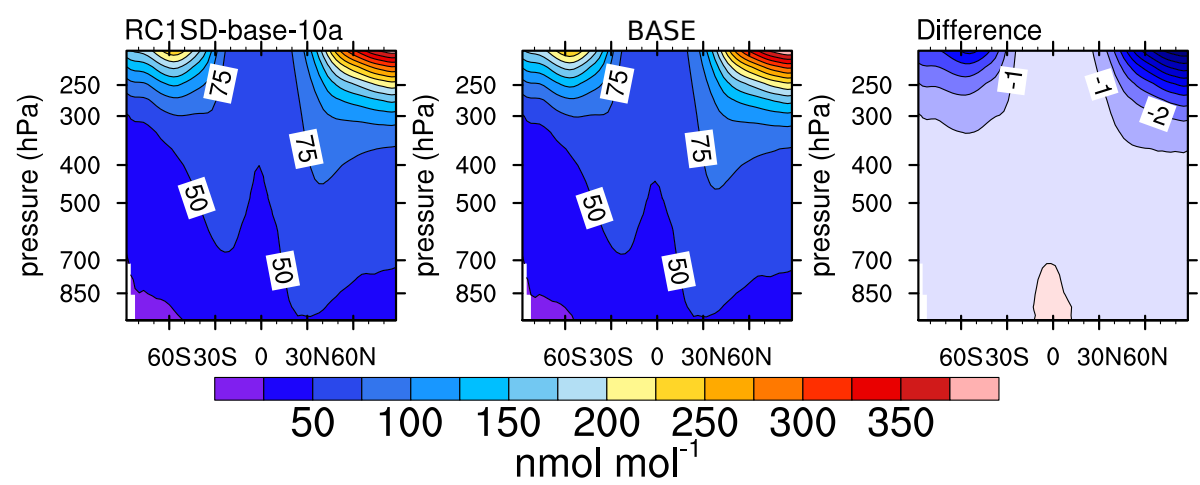

Figure S10: As figure S9 but for $\mathrm{O}_{3}$ (in $\mathrm{nmol} / \mathrm{mol}$ ). 


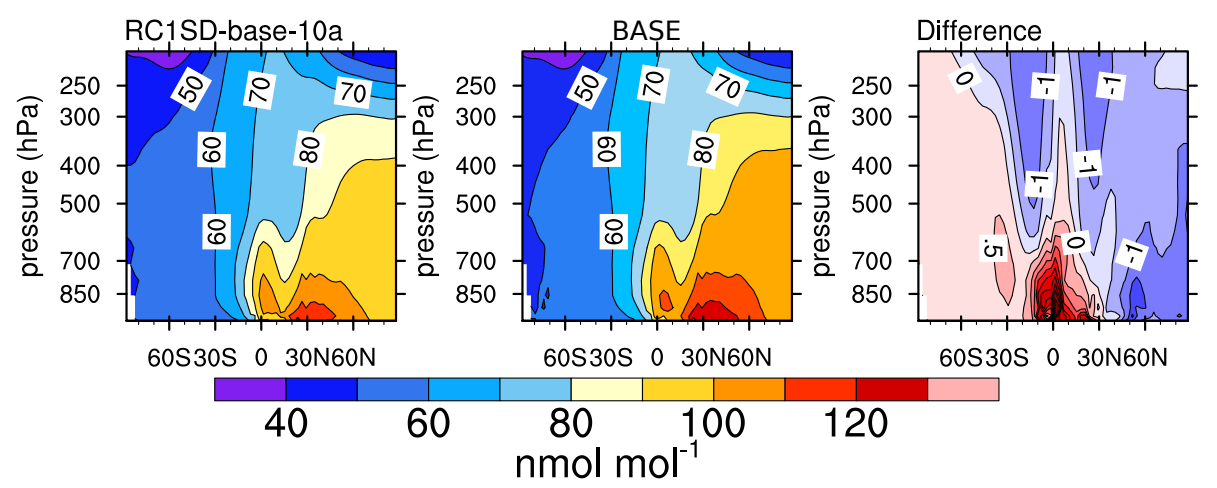

Figure S11: As figure S9 but for CO (in $\mathrm{nmol} / \mathrm{mol}$ ).

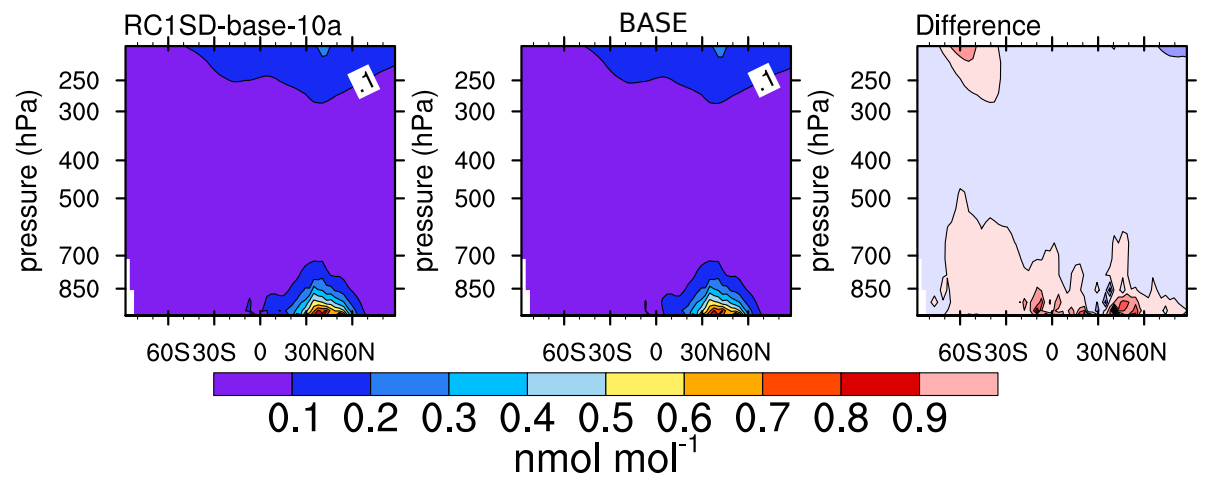

Figure S12: As figure $\mathrm{S} 9$ but for $\mathrm{NO}_{\mathrm{x}}$ (in $\mathrm{nmol} / \mathrm{mol}$ ). 


\section{S4 References}

\section{References}

Jöckel, P., Tost, H., Pozzer, A., Kunze, M., Kirner, O., Brenninkmeijer, C. A. M., Brinkop, S., Cai, D. S., Dyroff, C., Eckstein, J., Frank, F., Garny, H., Gottschaldt, K.-D., Graf, P., Grewe, V., Kerkweg, A., Kern, B., Matthes, S., Mertens, M., Meul, S., Neumaier, M., Nützel, M., Oberländer-Hayn, S., Ruhnke, R., Runde, T., Sander, R., Scharffe, D., and Zahn, A.: Earth System Chemistry integrated Modelling (ESCiMo) with the Modular Earth Submodel System (MESSy) version 2.51, Geosci. Model Dev., 9, 1153-1200, doi:10.5194/gmd-9-1153-2016, URL http://www.geosci-model-dev.net/9/1153/2016/, 2016. 